\title{
İkinci Dünya Savaşı'nın İç Politikadaki Yansımaları: Yaşanan Siyasi ve Ekonomik Sorunlar ${ }^{*}$
}

\author{
Abdullah iLGAZi ${ }^{* *}$
}

İkinci Dünya Savaşı́nın İç Politikadaki Yansımaları: Yaşanan Siyasi ve Ekonomik Sorunlar

Özet

Türkiye, bir taraftan İkinci Dünya Savaşı́nda izlediği dikkatli, temkinli bir dış politika ile savaş dışında kalarak savaş yıkımlarından korunurken, diğer taraftan da savaşın iç politika üzerindeki olumsuz etkileri nedeniyle ciddi sorunlarla uğraşmak zorunda kaldı. Savaş boyunca Türk basını hükümetin dış politika çizgisini izlemeye zorlandı. Savaşın Almanların aleyhine gelişmesi üzerine, Sovyetlerin savaşın başından beri rahatsızlıklarını açıkça ifade ettikleri Turancılar takibata uğradı ve tutuklandı. Savaş boyunca büyük bir ordunun hazır olarak bekletilmesi, henüz ekonomik gelişmesini tamamlamamış olan Türkiye'de ekonomik sıkıntıların boyutunu daha da genişletti.

Anahtar Kelimeler: Turancılar, Basın, Almanya, Sovyetler Birliği
Reflections of the Word War II on Turkey's Domestic Affairs: Political and Economic Problems Encountered

Abstract

With her cautious foreign policy, while Turkey avoided to enter in the Second World War on the one hand, she had faced with serious internal economic and political problems which were emanating from the war on the other hand. During the war, the Turkish press was dictated and obliged to support the government's foreign policy. When it became clear that Germany was to loose the war, the Turanians who had been under the Soviet radar for a long time, were chased and arrested. Moreover, maintaining a large army as a standby reserve throughout the war disrupted heavily the Turkish economy, as the country was still struggling to create a stabilized treasury.

Key Words: Turanians, Press, Germany, Soviet Union

\section{Giriş}

Türkiye, Milli Mücadele'nin başarıyla tamamlanması ve Lozan'da verilen diplomatik savaştan sonra ülkenin yaralarını sarmaya başladı. Bir taraftan İkinci Dünya Savaşı́nda izlediği savaş dışı politika ile savaşın ağır yıkımlarından korunmaya çalışırken, diğer taraftan da yanı başında cereyan eden olayları yakından takip ederek ortaya çıkan yeni gelişmelere göre dış politika çizgisini belirlemeye çalıştı. Almanya'nın ve İtalya'nın Avrupa'daki askeri faaliyetleri, buna karşılık Türkiye'nin İngiltere ve Fransa ile yakınlaşmasına yönelik yürüttüğü diplomatik ilişkiler, Sovyet Rusya ve Bulga-

${ }^{*}$ Bu makale, V. Askeri Tarih Semineri için hazırlanan, ancak sunulan bildiriler arasında yer almayan metnin yeniden gözden geçirilmesi ile hazırlanmıştır.

** Abdullah İLGAZi, Prof.Dr., Dumlupınar Üniversitesi, Tarih Bölümü, ailgazi65@hotmail.com, ORCID ID orcid.org / 0000-0002-4830-3014 
Abdullah ILGAZi

ristan ile imzalamış olduğu saldırmazlık paktları ve daha sonrasında Almanya ile imzalanan tarafsızlık anlaşması yeni dış politika anlayışının bir sonucuydu.

Türkiye'yi yöneten kadrolar, ülkenin içinde bulunduğu ağır ekonomik sorunların farkındaydılar ve bir an önce bu sorunların çözüme kavuşturulması gerektiğine inanıyorlardı. Bunun bir sonucu olarak kendilerinin sorumlu olmadığı bu savaşın dışında kalmak ve taraflarla iyi geçinmek temel ilke olarak benimsendi. Yine kabul etmek gerekir ki, diplomatik mücadelenin yürütülmesinde ve başarıya ulaşmasında Osmanlı geçmişinin ve geleneğinin büyük rolü oldu. Ekonomik yetersizliklere rağmen Osmanlı devletini uzun süre ayakta tutmak bu tecrübe sayesinde mümkün olabilmişti. İkinci Dünya Savaşı'nda Türkiye'nin dış politikasını belirleyenler bu diplomasi yeteneği ve birikiminden yararlandı.

Savaşın dışında kalmayı başarabilen Türkiye, muhtemel riskleri göz önüne alarak askeri tedbirlere de başvurdu. Seferberlik ilanıyla silahaltına alınan askerlerle birlikte büyük bir ordunun hazır olarak bekletilmesi, hükümetin Sovyet ve Alman ordularının askeri başarılarına göre iç politikaya ve basına müdahale etmesi, çeşitli sorunların yaşanmasına neden oldu.

\section{Ekonomik Sorunlar ve Alınan Tedbirler}

İkinci Dünya Savaş'ının olumsuz etkileri en çok ekonomik alanda yaşandı. Savaşın başlaması ile birlikte ülkede kısmî seferberlik başlatıldı. Yaklaşık bir milyon insanın askere alınması hazineye büyük bir ekonomik yük getirdi. Diğer taraftan tarım ve sanayide yaşanan iş gücü sıkıntısı toplum hayatını olumsuz yönde etkiledi. Bu gelişmeler Türk dış ticaretin hacminin önemli ölçüde azalmasına neden oldu. 1938 yılında ihracat 144,9, ithalat 149,8 milyon TL iken; 1941 yılında ihracat 123,8, ithalat 74,8 milyon TL'ye geriledi. (Tic. Bak., 1973, ss.52-53)

Ekonomik alanda görülen bu daralma, yatırımların azalmasına ve tüketim mallarında kıtlığa neden oldu. Diğer taraftan gelirleri azalan devletin nakit sorunlarını çözmek için sık sık Merkez Bankası'na başvurması üzerine, gelir gider dengesi bozuldu. Artan enflasyon sonucu oluşan aşırı fiyat artışları ve buna bağlı olarak ortaya çıkan hayat pahalılı̆ı halkı bunalttı.(Boratav,1982,ss.216217; Aydemir,1968,ss.224-224;Aydemir,1963) İsmet İnönü, 1 Kasım 1944'te bu sorunları şu sözlerle açıklıyordu: “...memleket içinde en büyük uğraşımız beslenme güçlükleri ve enflasyonun zararlarıyla oldu".(İnönü,1946,s.317)

Hükümet, savaşın ilk yıllarından itibaren bu olumsuzlukların etkilerini azaltmak için bazı tedbirler almaya başladı. Türk-Alman ilişkileri ülkenin ekonomik çıkarları gözetilerek yürütüldü.(Weisband,1974,ss.99-100) İngiltere ve Almanya arasında rekabet konusu olan Türk kromu ve tarım ürünleri sadece savaş malzemeleri karşılığında ihraç edildi.(ilgazi,1995,ss.134-140) Bu durum dış politikada önemli bir unsur haline geldi ve Türkiye'nin dış politikasını etkiledi. Ülke içinde alınan tedbirlerin bir kısmı önleyici ve kısıtlayıcı tedbirlerdi. Oldukça sert olan bazı tedbirlerden en çok köylü kesim etkilendi.(Weisband,1974,s.99) Köylerde yaşayan insanlar bu tedbirler nedeniyle bü- 
yük bir acı çektiler ve onların bu kırgınlıkları bir süre sonra Türk siyasetinde belirleyici bir rol oynayacaktır.

Hükümetin savaşın iç politika üzerindeki etkilerini ortadan kaldırmak için aldığı en önemli tedbirlerden biri Milli Korunma Kanunu'dur. İsmet İnönü’nün de desteklediği(İnönü,1946,s.317) ve 1924 Anayasası'nın 5. ve 8. maddesine dayandırılarak, 18 Ocak 1940 tarihinde çıkarılan bu kanun hükümete geniş yetkiler veriyordu.(Koçak,1986,ss.248-251;Lewis,1984,ss.295-296) Milli Korunma Kanunu ile hükümet, köylü vatandaşları insan gücünün eksikliğinin görüldüğü sanayi bölgelerinde çalışıırma yetkisi alıyordu. Uygulamada çok ciddi sorunlar yaşandı. Vatandaşların arzu etmediği yerlerde, özellikle maden bölgelerinde zorla ve çok düşük ücretlerle çalıştırılması büyük huzursuzluklara neden oldu.

Toprak Mahsulleri Ofisi'nin ${ }^{1}$ Milli Korunma Kanunu gereğince almış olduğu kararlar daha da sert oldu. Devlet, azalan buğday üretimi karşısında zorlayıcı tedbirlere başvurdu. Ofis, üretici olan vatandaşın elindeki mahsulü önceden tespit ediyor, ailenin ihtiyacını ve tohumluk kısmını ayırdıktan sonra geri kalan kısmına tespit ettiği fiyattan devlet adına el koyuyordu². Şehirde ekmek fiyatlarının yükselmesi ve hayat pahalılığı bu uygulamaya gerekçe olarak gösteriliyordu. Toprak Mahsulleri Ofisi'nin köylünün elindeki mahsulü serbest piyasadan daha düşük bir fiyatla satın alması büyük bir hoşnutsuzluğa neden oldu ${ }^{3}$. Bu durumda savaşın ağır faturası köylü vatandaşların omuzlarına yüklenmiş oldu.

Milli Korunma Kanunu tasarısının hazırlık aşamasında görev almış olan Şevket Süreyya Aydemir'in konuyla ilgili şu düşünceleri şu şekildedir. "Olağanüstü tanzim ve müdahale tedbirlerinin, hiç kimse gönülden savunucusu değildi. Adliye Vekâleti Müsteşarı, Teşkilat-ı Esasiye Kanunu'nun esas kanun olduğunu, bu kanunun vatandaşın mülkiyet haklarını, serbest tedarik ve satış haklarını koruduğunu, kısacası serbest ticareti kısıtlayacak devlet müdahalesine karşı olduğunu mevzuata göre haklı olarak açıklıyordu...".(Aydemir,1968, s.210)

İkinci Dünya Savaşı́nın iç politika üzerindeki önemli etkilerinden biri de kazançların vergilendirilmesi alanında yapılan düzenleme oldu. Kazançların vergilendirilmesi konusunda adil bir düzen-

\footnotetext{
${ }^{1} 23$ Temmuz 1933 tarih ve 3491 sayılı kanunla kurulan Toprak Mahsulleri Ofisi'nin kurulma amacı, ülkedeki tarım ürünlerinin devlet eliyle dengeli bir şekilde dağıtımını sağlamak ve çiftçiyi desteklemekti. Bu uygulama kuruluş kanunu ile uyuşmuyordu.

${ }^{2}$ Bu uygulama Milli Korunma Kanunu'nun 14.maddesine dayandırılarak yapılıyordu. İlgili madde hükmü şu şekildedir. "Her türlü maddelerin veya yardımcı malzemelerim muayyen ellerde toplanarak halk ve milli müdafaa ihtiyacının tasyıka düşürülmesine meydan vermemek için hükümet, değer fiyat mukabilinde bunlara el koymak ihtiyacı olan müesseselere karsız olarak tevzi edebilir." Kanun için bkz. Ayın Tarihi, No:76(Ocak 1940).

${ }^{3}$ Savaş döneminin ortaya çıkardığı zor şartlar göz önüne alındığında bazı zorlayıcı tedbirlerin alınmasını Türk köylüsü normal karşılamıştır. Ancak Toprak Mahsulleri Ofisi'nin bu uygulamalarına kuşkuyla bakılmış ve savaş yükünün eşit olarak yüklenilmediği kanaatine varmıştır. Bu olumsuz yaklaşım, CHP'nin iktidarda kalmasını zorlaştıracak ve Demokrat Parti'nin özellikle Türk köylüsü nezdinde desteğini artıracaktır. Nüfusun büyük bir kısmının köylerde yaşaması ve tarımla geçimini sağlaması Türk seçmenin siyasi tercihini etkileyecektir.
} 
leme yapılamadı. Ücretli kesimler vergilerini öderken, diğer taraftan serbest kesim ile savaş döneminde varlıklarının daha da artıran zenginler kendilerinden beklenen vergileri ödemediler. Kazançlarını düşük göstermek suretiyle az vergi ödeyen bu kesimler aynı zamanda savaş döneminde az bulunan bazı tüketim mallarını da stoklayarak değerinin çok üzerinde satma yoluna gittiler. İsmet İnönü ekonomiyi zorlayan ve ciddi şikâyetlere neden olan bu gelişmeleri, 1 Kasım 1942'de TBMM'ni açış konuşmasında şu sözlerle ifade ediyordu: “Şuursuz bir ticaret havası, haklı sebepleri çok aşan bir pahalılık belası, vatanımızı ıstırap içinde bulunduruyor. Bulanık zamanı bir daha ele geçmez zaman fırsat sayan eski batakçı çiftlik ağası ve elinden gelse teneffüs ettiğimiz havayı ticaret metaı yapmaya yeltenen gözü doymaz vurguncu tüccar... ve bazı politikacılar büyük bir milletin hayatını mayınlamayı denemektedirler.(İn̈nü,1946,ss.370-372)

İnönü’nün de ifade ettiği bu olumsuzlukların önüne geçmek için Saraçoğlu hükümeti olağanüstü bir uygulamaya geçti. Savaş döneminde elde edilen haksız servetin bir kısmını devlete aktarmak ve para politikalarını yönetmek için Varlık Vergisi Kanunu ${ }^{4}$ tasarısının hazırladı ve birkaç saatlik görüşmeden sonra kanunlaştı ${ }^{5}$. TBMM, bu kanunla, haksız yollarla elde edilen kazançlar ve yürürlükteki kanunlarla alınan vergilerin dışında kalan sermaye ile gelirlerden vergi alarak savaş dönemi askeri ihtiyaçların bir kısmı karşılanmak istendi. Diğer bir ifadeyle, savaş yıllarında ithal ettikleri malları istedikleri fiyatla satarak, karaborsa ve vurgunculuk yaparak haksız yere zengin olanlardan ek vergi almak ve bu suretle ekonomik sıkıntı içinde yaşayan fakir kesimler bir nebze tatmin edilmek istendi. Saraçoğlu da bu kanunun amacını, 'zengin tüccar ve emlak sahipleri gibi savaştan büyük paralar kazananlardan vergi toplamak' ${ }^{6}$ olarak açıkladı.

Bu kanun, büyük çiftlik sahiplerinden ve iş adamlarından ek vergi alınmasını öngörüyordu. Mevcut uygulamada çiftlik sahiplerinden $\% 5$ 'den fazla vergi alınamıyordu. Yeni uygulama ile bu oran değiştirildi ve iş adamları 1941 yılı net karları için \%50-70 arası vergi ödemekle sorumlu tutuldu. Diğer vergi mükelleflerinin durumu ise özel komisyonların takdirine bırakılacaktı. Vergilendirme ile ilgili itirazlar ise sadece TBMM'ye yapılabilecekti. (Ökte, 1952,ss.10-11)

Varlık Vergisi ilk günlerden itibaren tartışıldı ve Anayasa'ya aykırı olduğu ileri sürüldü. Varlık Vergisi'nin uygulanma biçimi hükümetin bu kanunla asıl hedefinin İstanbul ve İzmir'deki gayrı Müslimlerin Türk ekonomisi üzerinde etkilerini kırmak olduğunu ortaya koyuyordu. Böylece, Türklere dış ticarette yer açılacaktı. Nadir Nadi'nin şu sözleri bunu destekler mahiyettedir. "Kulaktan kulağa fısıldandığı, hatta zaman zaman yüksek sesle dile getirildiği gibi, daha da açıkçası, kanunun ikinci hedefi piyasayı azınlıkların denetiminden kurtarmak ve Türklere açmaktı... Türk vatandaşı olmakla

\footnotetext{
${ }^{4}$ Varlık Vergisi Kanunu için bkz. Düstur, Üçüncü Tertip, Cilt XXIV, s.8-15; Resmi Gazete, Sayı 5255(11 Kasım 1942); TBMM Zabıt Ceridesi, 6. Dönem, Cilt 28, 11 Kasım 1942, s. 20-32.

${ }^{5}$ Varlık Vergisi ile ilgili yapılan tartışmalar için bkz. TBMM Zabıt Ceridesi, 6. Dönem, Cilt 28, 11 Kasım 1942, s. 14-19.

${ }^{6}$ TBMM Zabıt Ceridesi, 6. Dönem, Cilt 28, 11 Kasım 1942, s. 28.
} 
övünen Yahudi, Rum ve Katolik vatandaşlarımız, emlak ve servetlerini yok pahasına elden çıkaracaklardı..."(Nadi,1964, ss.178-180)

Varlık Vergisi Kanunu bazı zorlayıcı tedbirler de öngörüyordu. Vergisini ödemeyenler basında teşhir edildi ve bunların Aşkale'ye yol yapımında çalıştırımak üzere gönderileceği ilan edildi. MaaşIılara, hasta ve yaşlılara uygulanan ceza hafifletildi ${ }^{7}$. 32 kişilik bir kafile 27 Ocak'ta Aşkale'ye gönderildi ${ }^{8}$. Varlık Vergisi'nin en çok tartışıldığı yerlerden biri olan İstanbul'daki uygulamaların başında bulunan Faik Ökte, bu uygulamayı bir facia olarak değerlendirmektedir. Defterdar olarak listelerin hazırlanmasında ve daha sonraki süreçte fiilen görev alan Ökte, konuyla ilgili düşüncelerini özetle şu şekilde ifade etmektedir. “...Varlık vergisi, Cumhuriyet mali tarihinin yüz kızartıcı bir sayfasıdır. Benimle birlikte arkadaşlar da bundan nefret ederlerdi...".(Ökte, 1942, Önsöz)

Varlık Vergisi uygulaması, kısa sürede ekonomik açıdan olumlu sonuçlar verdi. 1942 yılı bütçe gelirleri önemli ölçüde arttı. Bu artışta Varlık Vergisi'nin rolü \%70 oldu. Bu yıl hükümet bütçe açığı vermedi. Ancak 1943 yılından itibaren gerek kanunun uygulanmasında görülen aksaklıklar ve gerekse artan askeri harcamalar nedeniyle gelirler giderleri karşılayamayınca bütçe dengesi yeniden bozuldu.(Baydar,1978) Gayrı Müslim vatandaşlar haklarında komisyonlarca tespit edilen vergileri nakit olarak ödemede zorlanınca sahip oldukları varlıkların büyük bir kısmı devlete aktarıldı. Varlıkların bir kısmı da el değiştirerek Türklerin eline geçti. Rum, Ermeni ve Yahudilerin ellerindeki varlıkları düşük fiyatla elden çıkarmasıyla birlikte bilhassa İstanbul'daki ticaret ve sanayi dünyasının etnik yapısı değişti. Bütün bu gelişmeler bir taraftan Türkiye'ye yabancı yatıımların gelmesine engel olurken, diğer taraftan önemli bir sermayenin yurt dışına çıkmasına zemin hazırladı.

\section{Turancilık Sorunu}

Alman ordularının Sovyetler Birliği'nde Türk kökenli halkların yaşadığı bölgelere girmesi, Almanlara Türk iç politikasına yönelik propaganda yapma imkânı sağladı9.(Bilgin,2004,ss.12-15) Propaganda faaliyetleri Türkiye'deki Turancılar üzerinde etkili oldu. Başbakan Saraçoğlu, "Biz Türküz, Türkçüyüz ve daima Türk kalacağız. Bizim için Türkçülük bir kan meselesi olduğu gibi bir vicdan ve kültür meselesidir" (Deringil,1994,s.160) sözleriyle bu akımı desteklediğini ortaya koyuyordu. Alpaslan Türkeş'in şu sözleri de o günlerin siyasi atmosferini ortaya koymak bakımından önemlidir.

“iktidardaki Şükrü Saraçoğlu’nun milliyetçilik anlayışındaki ırkçılık dozuna ancak Hitlerin nasyonalizmindeki Cermen ırkçוlı̆̆ dozu denk gelebilirdi... Asker ve sivil yatılı okullara alınacak öğrenci-

\footnotetext{
7 Bkz. Ulus, 12 Ocak 1943.

${ }^{8}$ Bkz. 27/28 Ocak 1943 tarihli gazetelere.

922 Haziran 1941'de, Almanlar Sovyetlere savaş ilan ettikten sonra hızla Leningrad ve Kiev istikametinde saldırıya başladı. 19 Eylül-21 Kasım tarihlerinde bütün Kırım Almanların eline geçti. Ağustos ayın da ise Kafkas dağlarında Ebruz tepelerine kadar olan bölgeyi işgal eden Alman kuvvetleri Hazar denizine ulaşamadığı için Kafkasya ile Bakü’yü Rusya'dan ayırma fırsatını elde edemedi.
} 
lerin Türk ırkından olması en başta yer alıyordu... Bütün bunlar gösteriyor ki, 1944 yılı 3 Mayısına kadar Cumhuriyet idaresi Turancılığı uygulamaya çalışmış...".(Türkeş,1968,s.23)

Turanclık sorunu, Türk-Alman ilişkilerinde resmi belgelere de konu olmuş, Kafkasya'da bulunan Türk toplulukların yaşadığı bölgelerde tampon bir Türk devletinin kurulması düşüncesi iki taraf yetkilileri arasında tartışılmıştır.(Deringil,1994,ss.163-164) Her ne kadar hükümet yetkililerinden bazıları bu konuya ilgi duymuş olsa da, Devlet Başkanı İsmet İnönü’nün aynı çizgide olduğunu söylemek isabetli bir değerlendirme olmaz. Çünkü İnönü, bu durumun tehlikeli sonuçlarını görüyor ve herhangi bir toprak talebinde bulunmanın gerçekçi bir dış politika ile örtüşmeyeceğini her fırsatta dile getirmeye çalışıyordu. Alman ordularının başarıları devam ettikçe Turancıların faaliyetlerindeki yoğunluk artmış, hükümet de propaganda yapanlara karşı hoş görülü davranmıştır.

Buna karşılık, bir taraftan Almanya'nın cephelerde savaş kaybetmeye başlaması, diğer taraftan da yurt içinde yaşanan bazı gelişmeler hükümetin Turancılara karşı olan tavrını değiştirdi. Sovyet ordularının Alman kuvvetlerini durdurması ve karşı hücuma geçmesiyle birlikte Türkiye'nin Sovyet politikasında gözle görülür bir değişiklik yaşandı. Türk hükümeti Sovyetlerle arasında gerginliği artıracak her türlü hareketi baskı altına almaya başladı. Bilhassa Nihal Atsı'ın 20 şubat ve 21 Mart'ta Başbakan Şükrü Saraçoğlu'na hitaben yazmış olduğu iki mektup (Tevetoğlu,1964,ss.600605; Orhun,1 Nisan 1944) hükümetin Turancılara karşı harekete geçmesini hızlandırdı. Mektuplarda Başbakan'a hitaben, “...Bu satırların amacı, size Türkçülüğün neden yalnızca sözde kaldığını ve niçin bir eyleme geçilmediğini sormaktır”, diyordu.

Hükümete karşı bir hareket olarak değerlendirilen bu gelişmeden sonra Turancı öğrenciler şiddetli eylemler yapmaya başladı. Hükümet harekete geçip Turancı önderleri tutuklattı ${ }^{10}$. 9 Mayıs'ta Turancıların tutuklanmasından sonra İsmet İnönü, bütün yurtta yayınlanan konuşmasında, Türkiye' nin başkalarının topraklarında gözü olmadığını, Turancılar ve faaliyetlerinin Türkiye Cumhuriyeti için tehlike arz ettiğini ve Sovyetler Birliği'nin Türkiye'nin tarihi dostu olduğunu altını çizerek ifade etmeye çalıştı.

Aslında hükümetin bu şekilde tavır değiştirmesinin amacı bir grup vatandaşını cezalandırmak değildi. Asıl niyet, Sovyetleri kızdıracak davranışlardan kaçınmak ve yöneticileri yeni dönemde ölçülü davranmaya yöneltmekti. 1944 yılının Mayıs ayında tutuklanan Turancıların 31 Mart 1947' de suçsuz görülerek beraat etmesi, bu yaklaşımın doğru olduğunu göstermektedir.

\section{Basının Denetim Altında Tutulması}

Türk hükümeti, savaş boyunca basını kontrol altında tutmak için çeşitli yöntemlere başvurdu. Yürürlükteki kanun ve yönetmelikler hükümete geniş yetkiler veriyordu. 1931 tarihli Matbuat Kanunu, 1938 yılında değiştirilmiş ve getirilen yeni düzenlemeyle gazete ve dergi çıkarma izni en

\footnotetext{
${ }^{10}$ Nihal Atsız, Necdet Sançar, Zeki Velidi Togan, Reha Oğuz Türkkan, Hasan Ferit Cansever, Orhan Şaik Gökyay Ve Hamdi Sadi Özbek tutuklananlar arasında yer alıyordu.
} 
büyük mahalli amire bırakılmıştı ${ }^{11}$. Bu kanunun 34. maddesi, Devlet güvenliği ile ilgili konularda ve halkın devlete karşı güvenini sarsacak yazılar yazmasını kesinlikle yasaklıyordu. İlgili kanun maddesi, bu yasağa uymayanlara para ve hapis cezası öngörüyordu. 50. maddeye göre ise İcra Vekilleri Heyeti gazete ve dergileri süresiz kapatma yetkisine sahipti. Kapatma yetkisi ayrıca sıkıyönetim ilan edilen illerde mahalli yetkiliye bırakılmıştı.

Hükümet, Matbuat Umum Müdürlüğü vasıtasıyla gazetelerin ne zaman, hangi manşetlerle ve puntoyla çıkacağına karar verebiliyordu. Ayrıca yazarların bir kısmının aynı zamanda milletvekili olması bu denetimin bir başka boyutunu ortaya koyuyordu. Matbuat Kanunu iç ve dış politika konularında sınırlı bilgilere yer verilmesine imkân veriyordu. Gazetelerin başyazıları genellikle hükümetin politikalarıyla örtüşüyordu. Savaş ile ilgili gelişmelere sadece sınırlı ve sadece bir sütunda yer verilirdi. İç politikayla ilgili gelişmelerde hükümetin resmi açıklamalarıyla yetinmek zorunluydu. Milli Korunma Kanunu’na dayanılarak kâğıt tüketimi sınırlandıııldı. Sayfa sayılarının artırılması, özel günler hariç olmak üzere hükümetin iznine bağlıydı.

Bütün bunlara rağmen hükümet sözcüleri tarafından, savaş döneminde basının özgür olduğunu sık sık dile getirildi. Bu görüş birçok gazete ve yazarlarca da desteklendi. Ancak bu değerlendirmeleri daha çok dış kamuoyuna yönelikti.(Toker,1977;Nadi,1970;Yalman,1970) Basın denetim altında tutularak, hassas ve sürekli değişkenlik gösteren askeri ve diplomatik gelişmelerin ışı̆̆ında yürütülmek istenen dış politika stratejisinin bu haber ve yorumlardan zarar görmemesi amaçlandı. Basın alanındaki bu denetimin halk nezdinde olumlu bir karşıı̆ı olmadı. Bilhassa Turancıların ani bir kararla tutuklanması ve tutuklanmaların basında yanlı bir şekilde yer alması, halkın hükümete bakışını olumsuz yönde etkiledi.

Bir taraftan iç politikada bu gelişmeler yaşanırken, diğer taraftan savaşın ağır faturası günlük hayatı da etkiledi. Halkın muhtemel bir savaşa hazırlıkı olması için Ağustos ayında bir dizi tedbirler alındı(Öymen,1967, Milliyet, 8 Şubat; Üstündağ, 1955, ss.17-43) Alınan bu tedbirler Eylül ayında daha da hızlandııılı. Büyük binaların bodrum katları sığınağa dönüştürüldü. Evlerin bahçelerine sığınak kazma mecburiyeti getirildi. Zehirli gazlara karşı basın ve yayın organlarında sürekli uyarıcı açıklamalara yer verildi.

\section{Sonuç}

İkinci Dünya Savaş ve savaşın ortaya çıkardığı koşullar Türkiye'de iç politikayı etkiledi. Bu etki, en belirgin olarak ekonomi, basın ve siyasal yaşamda hissedildi. Hükümetin ekonomi politikaları gerek ekonomik altyapının yetersiz olması gerekse uygulamadaki aksaklıklar nedeniyle başarılı olamadı. Özellikle hububat ve ekmek sıkıntısı halk nezdinde büyük tepkilere neden oldu. Hükümetin bu sorunu çözmek amacıyla zorlayıcı tedbirler alması, köylü ve küçük üreticilerin yükünü daha da artırdı.

\footnotetext{
1128 Haziran 1938 tarihli bu düzenleme için bkz. Türkiye Cumhuriyeti Başbakanlığı, Son Değişikliklere Göre Matbuat Kanunu, Ankara 1946, s.446-465.
} 
Abdullah ILGAZi

Diğer yandan basının denetim altında tutulması ve buna uymayanların cezalandırılması Türk halkı tarafından hoş karşılanmadı. Turancılık faaliyetleri nedeniyle bir kııım aydınların ani bir kararla tutuklanması ve bu tutuklanmaların abartılı bir şekilde kamuoyuna duyurulması hükümete karşı olan güveni sarstı.

Hükümetin bu uygulamaları, Türkiye'nin siyasi hayatında etkili bir rol oynadı ve halkın siyasi tercihini değiştirdi. Özellikle nüfusun yoğun olarak yaşadığı kırsal alanlarda hükümete karşı oluşan bu tepki, 1950'li yıllarda Demokrat Parti'nin halk nezdindeki desteğini artırdı ve devamında iktidar değişikliğinde önemli bir rol oynadı.

\section{Kaynaklar}

Aydemir, Ş. S. (1963). Türkiye’de Bütçe Hareketleri, Ankara: IKA Ajansı Yay.

Aydemir, Ş. S. ( (1968). Ikinci Adam, 2. Baskı, İstanbul 1968

Baydar, E. (1978). İkinci Dünya Savaşı lçinde Türk Bütçeleri, Ankara: Maliye Bakanlığı Yay., No 1978198.

Boratav, K. (1982). Türkiye'de Devletçilik, Ankara: Savaş Yayınları.

Bilgin, M. S. (2004). “ikinci Dünya Savaşı Sonrası Uzak Şark Türklerinin Sovyet Esareti Altına Düşmesi ve Ayaz İshaki'nin Siyasi Mücadelesi”, Türk Dünyası Tarih Kültür Dergisi, 216, ss.1215.

Deringil, S. (1994). Denge Oyunu, İstanbul: Tarih Vakfı Yurt Yayınları.

İlgazi, A. (1995). İkinci Dünya Savaşı́nda Türkiye'nin Dış Politikası, İstanbul: Basılmamış Doktora Tezi, İstanbul Üniversitesi, AiiT Enstitüsü.

İnönü, i. (1946). Inönü’nün Söylev ve Demeçleri, İstanbul: Cilt I, MEB Yay.

Koçak, C. (1986). Türkiye'de Milli Şef Dönemi, Ankara: Yurt Yayınları.

Koçak, C. (1986). İkinci Dünya Savaşı ve Türk Basını", Tarih ve Toplum, 35, ss.29-34.

Lewis,B.( 1984). Modern Türkiye’nin Doğuşu, Çev. Metin Kıraatlı, Ankara: İkinci Baskı, TTK Yay.

Nadi, N. (1964). Perde Aralığından, İstanbul: Cumhuriyet Matb.

Nadi, N. ( (1974). Perde Aralığından, İstanbul: Çağdaş Yay.

Ökte, F. (1952). Varlık Vergisi Faciası, İstanbul: Nebioğlu Yay.

Öymen, A. (1967). “ikinci Dünya Savaşında Türkiye”, Milliyet( 8 Şubat 1967).

Tevetoğlu, F. (1964). Türkiye'de Sosyalist ve Komünist Hareketler 1910-1960, Ankara: Ayyıldız Matb. A 
Ticaret Bakanlığı (1973). Ticaret Bakanlığı ve 50. Yılı, Ankara: Ticaret Bakanlığı Yay. ss.52-55.

Toker, M. (1977). Tek Partiden Çok Partiye, İstanbul: Milliyet Yayınları.

Türkeş, A. (1968). 1944 Milliyetçilik Olayı, İstanbul: Yaylacllık Matb.

Türkiye Cumhuriyeti Başbakanlığı(1946). Son Değiş̧ikliklere Göre Matbuat Kanunu, Ankara: T.C. Başbakanlık Yay.

Üstündağ, Z. (1955). “ikinci Dünya Harbinde Türkiye”, Ordu Dergisi, LXXV, 179, ss.17-43.

Weisband, E. (1974). İönü’nün Dış Politikası, Çev. M. Ali Kayabal, İstanbul: Özaydın Matb.

Yalman, A. E. (1970). Gördüklerim, Geçirdiklerim, Cilt III(922-1944), İstanbul: Rey Yay.

\section{Süreli Yayınlar}

Ayın Tarihi, No:76 (Ocak 1940).

Düstur, Üçüncü Tertip, Cilt XXIV.

Resmi Gazete, Sayı 5255 (11 Kasım 1942).

TBMM Zabıt Ceridesi, 6. Dönem, Cilt 28, 11 Kasım 1942.

Ulus, 12 Ocak 1943.

Orhun, 15 ( 1 Mart 1944) ve 16 ( 1 Nisan 1944).

Tarih ve Toplum, 35 (Kasım 1986)

Ordu Dergisi, LXXV, 179 (1955)

Türk Dünyası Tarih Kültür Dergisi, 216, (2004) 